\title{
The Study of the Resource- Environmental Carrying Capacity in the Yellow River Delta
}

\author{
Kuifeng Wang ${ }^{1,2,3, a}$, Meng $\mathrm{Xu}^{1, \mathrm{~b}}$ \\ ${ }^{1}$ Shandong Institute and Laboratory of Geological Sciences, Shandong Key Laboratory of \\ Geological Process and Resource Utilization in Metallic Minerals, Key Laboratory of Gold \\ Mineralization Process and Resource Utilization Subordinate to the Ministry of Land and Resource, \\ Jinan 250013, China \\ ${ }^{2}$ School of Civil Engineering, Shandong University, Jinan 250061, China. \\ ${ }^{3}$ Key Laboratory of Carrying Capacity Assessment for Resource and Environment, Ministry of Land \\ and Resources (Chinese Academy of Land and Resource Economics, China University of \\ Geosciences Beijing)Beijing,101149 \\ amaplewkf@126.com b522903567@qq.com
}

Keywords: environment quality, environmental quality, Environmental carrying capacity

\begin{abstract}
To realize the sustainable development of the Yellow River delta regional economic, must improve the environmental quality, improve the resource environmental bearing capacity. This study used principal component analysis (pca) method to evaluate resources environmental bearing capacity of dongying city in 2011-2015. Results show that the time scale, the highest scores are guangrao county, dongying district in 4 annual ranking second, hekou and kenli district in 2012-2015 has remained low scores, indicating that hekou and dongying district in dongying city of the resource environmental bearing capacity need more attention, should incorporate hekou and kenli area in key monitoring area..
\end{abstract}

\section{Introduction}

Construction the resource-conserving and environment-friendly society which based on the capacity of resource environment, rule by natural law, aiming at the sustainable development has risen to the national strategy. It is represented by a set of indicators, to reflect the relationship between economic and resource development with environmental protection. The resource environment bearing capacity evaluation contains the virtues or defect degree of resource endowment and environmental capacity, and the matching degree of resource environment capacity and social economy development .resource endowment and the environment capacity, the resource environment is the match between capacity and social economy development(LI, Na, et al., 2016; Huang Bingjie et al, 2012; Huang Jie, 2014; Wang Gengyun, 2015; Wang Wei, 2012; ZhouWei et al, 2015).

Dongying city is the important resources and core city of the Yellow River delta efficient ecological economic zone. Dongying city is the center of the Yellow River delta, the ecological environment was weak, and the resource and environmental bearing capacity was low. We must improve resource and environmental bearing capacity, in order to realize the economic sustainable development of the Yellow River delta regional. At present, the resources and environment carrying capacity evaluation research for river delta and oil and gas resources city which is very important and particular has not yet published related research reports. On the basis of the development characteristics and difficulties survey of Yellow River delta and coastal zone oil and gas resources city, this study established the resources and environmental bearing capacity evaluation index system model and evaluation method of the typical city in this area. This study provides an objective evaluation for the establishment of urban sustainable development strategy (GAO Yanliang, 2011; WANG Cunlong et al, 2014 ;). 


\section{The Construction of Index System}

The resources and environment carrying capacity comprehensive evaluation research index system frame of Dongying city is formed by the target and index layer two levels. Target layer refers to the goal of resources and environment carrying capacity evaluation, according to the resources and environment carrying capacity evaluation elements, it can be determined for two kinds of rule layer of the resources and environment and social economy index system. Index layer was formed by the index which could reflect the characteristics of things in a certain respect and status indicators independently, there are both quantitative indicators and qualitative indicators, to strive the index comprehensive scientific representative. This research selected indexes of resources and environment and social economy, as shown in table 1.

Table 1. Resources and environment carrying capacity comprehensive evaluation index system

\begin{tabular}{|c|c|c|}
\hline Target layer & $\begin{array}{c}\text { Index } \\
\text { attribute }\end{array}$ & Index layer \\
\hline \multirow[t]{2}{*}{$\begin{array}{l}\text { Resource and } \\
\text { Environmental } \\
\text { indicators }\end{array}$} & $\begin{array}{l}\text { Positive } \\
\text { index }\end{array}$ & $\begin{array}{l}\text { N1 Resources abundance of oil and gas, N2 Per capita area of available } \\
\text { cultivated land, N3 Land development intensity (The proportion of } \\
\text { construction land area), N4 Total water consumption, N5 Repeat } \\
\text { utilization rate of industrial water, N6 Irrigative water effective } \\
\text { utilization coefficient, N7 Qualified rate of industrial waste water } \\
\text { discharge, N8 Decontamination rate of urban refuse, N9 Qualified rate } \\
\text { of centralized drinking water sources quality, N10 Fineness rate of air } \\
\text { quality, N11 Solid waste comprehensive utilization rate, N12 Per capita } \\
\text { area of urban greenbelt, N13 Forest coverage rate, N14 Wetland area } \\
\text { relative ratio, N15 Relative area of all kinds of ecological reserve }\end{array}$ \\
\hline & $\begin{array}{l}\text { Inverse } \\
\text { index }\end{array}$ & $\begin{array}{c}\text { N16 Mean annual concentration of inhalable particle, N17 Mean annual } \\
\text { concentration of } \mathrm{SO}_{2}, \mathrm{~N} 18 \text { Mean annual concentration of } \mathrm{NO}_{2}, \mathrm{~N} 19 \\
\text { Shoreline development intensity, N20 Regional crustal stability, N21 } \\
\text { Geological disasters risk, N22 Pollution level of water and soil caused } \\
\text { by oil }\end{array}$ \\
\hline $\begin{array}{l}\text { Economic } \\
\text { indicators }\end{array}$ & $\begin{array}{l}\text { Positive } \\
\text { index }\end{array}$ & $\begin{array}{c}\text { N23 Environmental governance investment as a share of GDP, N24 Per } \\
\text { capita GDP, N25 Fiscal revenue as a share of GDP, N26 Growth rate of } \\
\text { investment in fixed assets, N27 Disbursement of foreign capital, N28 } \\
\text { Total export-import volume, N29 Urban per capita disposable income, } \\
\text { N30 Per capita living space, N31 Industrial output, N32 Engel } \\
\text { coefficient }\end{array}$ \\
\hline
\end{tabular}

\section{Data resource, evaluation methods and empirical analysis}

\section{1 data resource}

The resources and environment indexes in this system included qualitative and quantitative indexes, and the social and economic indexes in this system were all quantitative indexes. Quantitative indexes were calculated with the data which mainly referred to Shandong Statistical Yearbook, Dongying Statistical Yearbook, Dongying Yearbook, Yearbook of Counties of Dongying, National Economy and Society Developed Statistical Bulletin of Dongying, China Environmental Statistics Yearbook, Dongying Water Gazette and Dongying Environment Gazette in 2011-2016. Qualitative indexes were mainly graded through various industries investigation and study reports (GAO Yanliang, 2011; SONG Jiekun et al, 2006; WAN Hong, 2010;) in recent years, their credibility and reliability were high.

\section{2 evaluation methods}

Principal Component Analysis (PCA) is a kind of objective and reasonable analysis method, and it have the advantages to reduce the workload of index selection, eliminate the mutual influence between the various indicators, simplify the determination of index weight. Therefore, our research chose this method to analysis the Yellow River delta center city (Dongying) resource and environmental carrying capacity composite level. 


\subsection{The calculation of comprehensive evaluation index}

Correlation analysis results showed that most of the indicators show significant linear correlation, it suggested the information has overlap between indexes. So, this research is suitable for using the PCA method to comprehensive evaluation the resource and environmental bearing capacity level of Dongying city from 2011 to 2015. In the process of evaluation analysis, we reflected the twodimensional characteristics of space and time: On one hand, to analysis the resource and environmental bearing capacity of five different counties in Dongying city in the same annual; on the other hand, to compare the resource and environmental bearing capacity of 2011-2015 annual in the same area. This analysis improved the accuracy and breadth of result from the time dimension and space dimension.

\section{4 computing resource environmental bearing capacity of Dongying city}

We used the PCA method in SPSS Statistics 21 software to comprehensively evaluate the resource environmental bearing capacity evaluation level of five counties in Dongying city respectively from 2011 to 2015, to analyze the resource environmental bearing capacity evaluation level every year in different parts (CHEN Xianpeng, 2015; WANG Qinmei et al, 2015).

Four main component total load amount to $100 \%$, the first principal component accounted for $44.469 \%$, the second principal component accounted for $24.404 \%$, the third principal component accounted for $17.797 \%$, the fourth principal component accounted for $13.329 \%$. This principal component has high degrees of explanation for raw data. We could determine each principal component reflects indicators by the amount of load per index and principal component (table.2).

Table 2. explains the total variance

\begin{tabular}{c|c|c|c|c|c|c}
\hline \multirow{2}{*}{ Component } & \multicolumn{3}{|c|}{ Initial Eigenvalues } & \multicolumn{3}{c}{ Extraction of sum of squares loaded } \\
\cline { 2 - 6 } & Total & Variance \% & Accumulation \% & Total & Variance \% & Accumulation \% \\
\hline 1 & 13.341 & 44.469 & 44.469 & 13.341 & 44.469 & 44.469 \\
2 & 7.321 & 24.404 & 68.873 & 7.321 & 24.404 & 68.873 \\
3 & 5.339 & 17.797 & 86.671 & 5.339 & 17.797 & 86.671 \\
4 & 3.999 & 13.329 & 100.000 & 3.999 & 13.329 & 100.000 \\
\hline
\end{tabular}

Resource environmental bearing capacity evaluation of each index, standard value, the correlation coefficient matrix, the initial eigenvalue, the percentage of variance and cumulative percentage of variance and principal component score coefficient matrix, etc. of five counties in Dongying city in 2012-2015 can be computational analysis by SPSS software. And the resource environmental bearing capacity evaluation value scores of 5 counties of Dongying city in 2012-2015 was obtained by calculate, and shown in the followed table and table 3.

Table 3. Resource environmental bearing capacity evaluation value scores in dongying city 5 counties

\begin{tabular}{cccccc}
\hline $\begin{array}{c}\text { Region } \\
\text { Yea凡 }\end{array}$ & Guangrao County & Dongying District & Lijin County & Kenli District & Hekou District \\
\hline 2011 & 2.876823 & 0.754511 & -1.13214 & -1.18944 & -1.30975 \\
\hline 2012 & 2.687754 & 1.281894 & -0.49708 & -1.61743 & -1.85514 \\
2013 & 3.016594 & 0.89938 & -0.60019 & -1.09191 & -2.22387 \\
2014 & 3.271676 & -0.30782 & -0.04278 & -0.70891 & -2.21216 \\
2015 & 1.94325 & 1.612147 & -0.33069 & -0.64663 & -2.57808 \\
\hline
\end{tabular}

\section{Conclusion}

It can be seen from the resource environment bearing capacity evaluates the composite score of 2011-2015 in five counties of Dongying city, in this five years, Guangrao county's overall score was always the highest, Dongying district was ranked second in 4 annual, Hekou and Kenli district were remained low scores in 2012-2015, indicating that in Dongying city resource environmental bearing capacity of Hekou and Kenli district need more attention, we can put the Hekou and Kenli district included in the key monitoring area. 
Considering the index setting and data analysis, the reasons of the low resources and environment carrying capacity scores of Hekou and Kenli district may be that the two counties were the key area of oilfield distribution in Dongying city, the oil and gas, water and soil pollution in this area was wide, pollution degree is high. And there is less investment in ecological and environmental governance, the social and economic value of two counties was low, less money was invested in ecological and environmental governance. In addition, the unused land area of the two regions is large, and the output of per unit area is relatively small, so the weights in the overall evaluation are relatively large, leading to a low overall score results, these respects were the short board and unfavorable factors to affect the whole comprehensive evaluation index score value.

\section{Acknowledgments}

This work was financially supported by National Natural Science Foundation of China (41602356),Open project of Key Laboratory of resources and environment carrying capacity evaluation of Ministry of land and resources (CCA2016.08), Shandong Provincial Geological Prospecting Fund Project (2013 (55), 2016 (07))

\section{References}

[1]. Li N, Wang K. 2016. Evaluation of coordinated development of regional resources and economy around Shandong Peninsula urban agglomerations. Journal of Groundwater Science and Engineering, 4 (3): 220-230.

[2]. Chenxianpeng. 2015. Evaluation of Resource and Evrionment Carrying Capacity of Land based on Principal Componet Analysis and Systemic Dynamic Model-A case Study of Yiwu city in the Zhejiang Province. Hangzhou city: Zhejiang University.

[3]. Gaoyanliang. 2011. Evaluation on the Ecological Environment and the Sustainable Development Research of Dong Ying City. Tianjin city: Tianjin University.

[4]. Huangjie. 2014. Carrying Capacity Analysis on Resources and Environment in central Plains Urban Agglomeration [D]. Wuhan city: Huazhong normal university).

[5]. Wanhong. 2010. Research on Wetland Information Extraction and Analysis of Yellow River Delta Based on RS and GIS. Qingdao: China University of Petroleum.

[6]. Wanggengyun. 2015. Research on Regional Economic Coordinated Development Based on Resource Environment Capacity - Take Yue and Yu as An Example. Hangzhou city: Zhejiang University. 